\title{
Variations of Tooth Root Morphology in a Romano- British Population
}

\author{
Alan H. Brook* and Marlene Scheers \\ School of Dental Studies, University of Liverpool, United Kingdom
}

\begin{abstract}
Tooth morphology can provide valuable evidence in studies of prehistoric, historic and modern populations. The aims of this study were to derive data for root anomalies in a Romano-British population, to investigate associations between anomalies, and to compare findings with other populations to provide evidence concerning etiology. An additional aim was to develop further the methodology and reproducibility in such studies. From the Christian cemetery of 3rd-5th century AD in Poundbury, UK, 385 skulls were suitable for examination. Radiographic technique was standardized with custom-made skull supports and criteria established for each anomaly. There was a high level of reproducibility for the diagnosis of each anomaly.
\end{abstract}

Tooth root morphology can provide valuable additional evidence to crown morphology in studies of prehistoric, historic and modern populations. The determination of root morphology may be multifactorial, as is crown morphology, with both genetic and environmental factors involved (Winter and Brook, 1989). Variations of root morphology include the number of roots, as with accessory roots or fused roots, their shape, as in taurodontism, or their size. Ethnic differences in root morphology have been recognized (Dixon and Stewart, 1976).

The present study aimed to derive data for root anomalies in a homogeneous Romano-British population and to investigate associations with other dental anomalies in this group. Also the study aimed to develop further the methodology of measurement and the reproducibility of diagnosis of root anomalies in archeological material, enhancing comparisons with other ancient and modern populations.

\section{MATERIALS AND METHODS}

The skulls investigated were from a cemetery of the Roman town of Durnovaria, close to the site of the modern Poundbury, Dorset, UK. The cemetery dates from the 3rd to 5th century AD and is of a Christian character. The population was of native British origin throughout this period (Farwell and Molleson, 1993).
The prevalence of the anomalies in individuals was: three-rooted mandibular first molars 1.8\%, fused roots $14.0 \%$, cuneiform roots $16.9 \%$, taurodontism $26.9 \%$, and invaginated teeth $1.1 \%$. There were highly significant $(\mathrm{P}<0.001)$ associations between fused and cuneiform roots, and both were significantly associated with third molar hypodontia $(\mathrm{P}<0.002$; $\mathrm{P}<0.05)$. These reductions in root morphology were commonly bilateral and more frequent in females, as is hypodontia. The findings of this study are compatible with a multifactorial etiology of these anomalies, showing continuous variation in root morphology. The gradients of anomalies observed are also compatible with the concept of morphogenetic fields. Dental Anthropology 2006;19(2):33-38.

The excavated skulls are housed at the British Museum (Natural History), London, UK. The total collection from this burial site consists of 1,100 crania, but a large proportion of these are very fragmented and unsuitable for this study. The criterion for inclusion in the present investigation was a jaw that had at least one permanent molar and one permanent incisor present. Juvenile skulls with a dental age of less than 9 years were excluded. The resultant sample was 385 skulls suitable for examination of root morphology.

Age and sex determinations were made by the staff of the British Museum based on the long bones, pelvic girdles and skulls. Of the sample, $40.0 \%$ (154) were estimated male, $38.7 \%$ (149) female, and for $21.3 \%$ (82) no determination could be made.

Radiographs were taken of all teeth using an industrial apparatus and Kodak ultraspeed dental occlusal films. A pilot study established the optimum voltage, current and exposure time as well as the standardized positioning of the x-ray tube, skull and films. Customized wooden blocks were developed for positioning the skulls. A total of 6 films per skull

${ }^{*}$ Correspondence to: A. H. Brook, School of Dental Studies, Edwards Building, University of Liverpool, Pembroke Place, Liverpool L69 3GN, UK

Email: a.h.brook@liverpool.ac.uk 


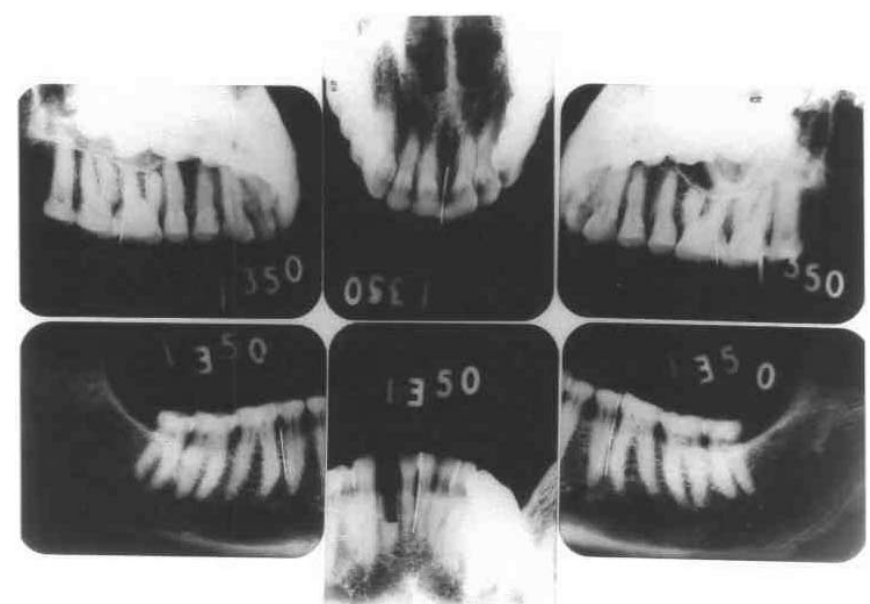

Fig. 1. Full coverage of the dentition using six radiographs.

provided full coverage of the teeth (Fig. 1). To calibrate measurements, all films were taken including a $20 \mathrm{~mm}$ length of orthodontic wire. The films were developed and viewed under standardized conditions.

The anomalies diagnosed were three-rooted mandibular first permanent molars, fused (pyramidal) and cuneiform roots, taurodontism and crown and root invaginations.

The radiographic criteria for the five anomalies diagnosed in the study were: (1) three-rooted mandibular first molar: evidence of a third root; (2) fused molar root: a pyramidal root form with no evidence of an interradicular bony septum or periodontal ligament but with separation of root canals; (3) cuneiform molar root: a root form with a central root canal whose shape followed the root outline; (4) taurodontism: criteria of Holt and Brook (1979; Fig. 2); and (5) crown invaginations: criteria of Hallett (1953); types 2, 3 and 4 were scored following Grahnen et al. (1959) and Brook (1974).

For each anomaly, prevalence for skulls, prevalence for teeth, sex distribution, and symmetry were investigated.

To test the reproducibility of the diagnosis, the radiographs of $20 \%$ of the sample were read on a second, separate occasion. The reproducibility findings are in Table 1.

\section{RESULTS}

The findings for the prevalence for skulls and sex distribution of the root anomalies studied are shown in Table 2, which also indicates the number of individuals suitable for scoring each anomaly.

Three-rooted mandibular first molars - those with an accessory root-had a prevalence of $1.8 \%$ of skulls and a tooth prevalence of $1.5 \%$. In half of the individuals the anomaly was bilateral and equal numbers of males

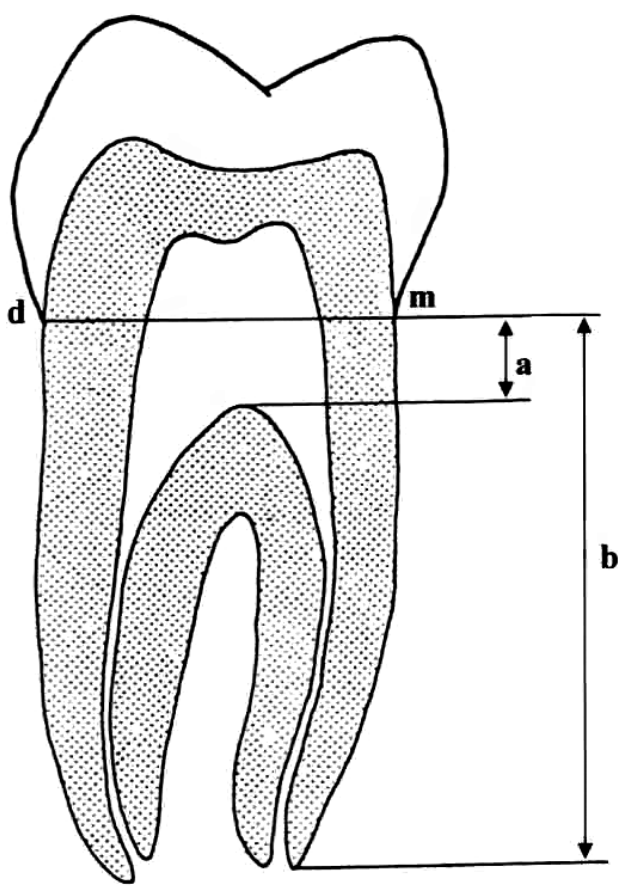

$\begin{aligned} \text { Baseline }= & \text { axis between mesial and distal points of } \\ & \text { amelo-cemental junction. } \\ \mathrm{a}= & \text { distance from baseline to highest point on } \\ & \text { pulp chamber floor. } \\ \mathrm{b}= & \text { distance from baseline to apex of distal } \\ & \text { root. }\end{aligned}$

Fig. 2. Measurement used for taurodontism (after Holt and Brook, 1979).

and females were affected.

For reduction in root number the prevalence for fused roots was $14.0 \%$ of skulls and for cuneiform roots was $16.9 \%$ of skulls. The tooth prevalence for reduced root number was $2.7 \%$ for fused roots and $3.4 \%$ for cuneiform roots, some individuals possessing both anomalies. Maxillary molars were affected more frequently than mandibular molars. Third molars were more often affected than second molars, with no example being found in first permanent molars. The male to female ratios of 1:2.2 for fused roots and 1:2 for cuneiform roots were statistically significant $(\mathrm{P}<0.02$ and $\mathrm{P}<0.01$, respectively). In $30 \%$ of affected skulls these anomalies were bilateral, and occasionally a fused root was seen on one side of the dental arch with a cuneiform root on the contralateral tooth.

Taurodontism was found in $26.9 \%$ of skulls, with a tooth prevalence in lower molars of $11.7 \%$. Third molars were the teeth most often affected and first molars the least. Taurodontism was bilateral in $47 \%$ of affected skulls. The male to female ratio was 1:0.67 and statistically significant $(\mathrm{P}<0.05)$. The differences between mean values of a and of a:b ratios (Fig. 2) in those teeth showing taurodontism compared to 
TABLE 1. Reproducibility of measurements and diagnosis

A. Clinical diagnosis

\begin{tabular}{lccc}
\hline \multicolumn{1}{c}{ Feature } & $\begin{array}{c}\text { No. diagnosed on } \\
\text { first occasion }\end{array}$ & $\begin{array}{c}\text { No. diagnosed on } \\
\text { second occasion }\end{array}$ & $\begin{array}{c}\text { No. diagnosed on } \\
\text { on both occasions }\end{array}$ \\
\hline Three-rooted & 1 & 1 & 1 \\
mandibular first molars & 11 & 13 & 11 \\
Fused molar roots & 16 & 15 & 15 \\
Cuneiform molar roots & 1 & 1 & 1 \\
Invaginations $21 \mid 12$ & & & \\
\hline
\end{tabular}

B. Using ratios

\begin{tabular}{ccc}
\hline Feature & $\begin{array}{c}\text { No. of teeth } \\
\text { measured }\end{array}$ & $\begin{array}{c}\text { No. within } 0.5 \text { of } \\
\text { ratio on first reading }\end{array}$ \\
\hline Taurodont mandibular molars & 272 & 212 \\
\hline
\end{tabular}

those without were highly significant $(\mathrm{P}<0.001)$. For measurement $b$, the differences were statistically significant for second molars $(P<0.01)$ and third molars $(\mathrm{P}<0.001)$.

The prevalence of invaginated teeth was 1.1\% of skulls. All invaginations in this sample occurred in maxillary lateral incisors. There was no evidence of periapical bone loss in relation to the crown invaginations that were all of the mild Hallett (1953) Class 2 category. No example of root invaginations was seen in this study.

The statistically significant associations between anomalies in this study were between fused and cuneiform molar roots $(\mathrm{P}<0.001)$ and between taurodontism and fused molar roots $(\mathrm{P}<0.05)$. Using results from a study of anomalies of tooth number and size in this population (Brook and John, 1995) statistically significant associations were found between congenital absence of third molars and fused molar roots $(\mathrm{P}<0.02)$, cuneiform molar roots $(\mathrm{P}<0.05)$, and taurodont lower molars $(\mathrm{P}<0.001)$.

\section{DISCUSSION}

The high level of reproducibility of measurements and diagnosis suggests that the present data are reliable within the constraints of the sample (Table 1). Comparisons with other historic and modern sample findings are therefore worthwhile.

In other studies of three-rooted mandibular first molars either radiographs (Souza-Freitus et al., 1971) or extracted teeth (Curzon, 1973) have been used. The radiographs in the present study were of good quality (Fig. 1) having been carefully standardized in the pilot study. For Caucasians the findings for three-rooted mandibular first molars have usually been of the order of $1 \%$ of individuals affected, while the frequency in Mongoloid peoples is much higher (Scott and Alexandersen, 1992). The Romano-British figure of $1.8 \%$ conforms to modern Caucasian results reviewed by Alexandersen (1963).

The criterion used for the diagnosis of cuneiform roots is shown by Holt (1976) to be highly reproducible, especially in lower molars. In this study, the one reversal of diagnosis (Table 1) was a maxillary molar that on the second occasion was diagnosed as having a fused root. The criterion for fused molar roots was adapted from Brabant and Kovacs (1961) and provided an acceptable degree of consistency (Table 1).

Similar to Brabant and Kovacs (1961), the highest frequency of cuneiform roots was found in maxillary third molars. For mandibular second molars the Romano-British prevalence was $3.2 \%$ of skulls, comparable to the findings of Pedersen (1949) in EastGreenland skull material and of Holt (1976) based on Brook's (1974) large population sample of modern British Caucasian schoolchildren. Reduction in root number affecting first permanent molars would seem to be rare as no example was found in these RomanoBritish skulls or by Pedersen (1949), Holt (1976) or Molnar and Horvath (1995).

The tendency for a bilateral occurrence of anomalies of reduced root number is found in other studies also, with the same trend for fused and cuneiform roots to occur in antimeric teeth where each anomaly was not bilaterally symmetrical (Holt, 1976; Ross and Evanchik, 1982; Tamse and Kaffe, 1981; Molnar and Horvath, 


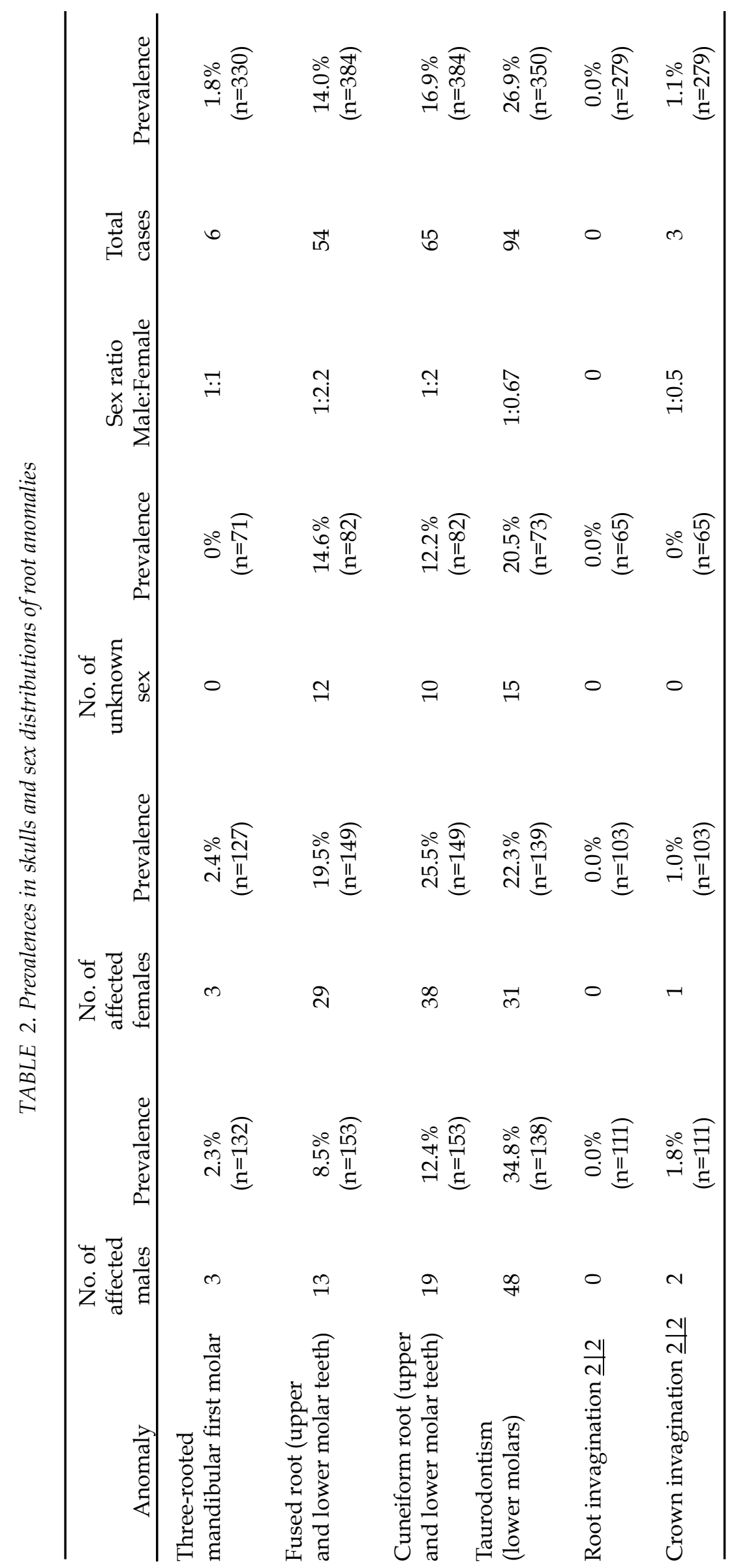


1995). There is also agreement that these anomalies are more common in females than males (Brabant and Kovacs, 1961; Holt, 1976; Ross and Evanchik, 1981; Table 1).

For taurodontism, comparisons are limited by the use of different criteria in different studies. Using the same methodology as the present study, Holt and Brook (1979) found that $6.3 \%$ of 1,115 modern British Caucasian schoolchildren had a taurodont mandibular first permanent molar compared to $1.8 \%$ of the Romano-British skulls. The prevalence and degree of taurodontism is often greater in second and third molars (Molnar and Horvath, 1995); in the present Romano-British sample the prevalence was $26.9 \%$ of skulls. Shifmann and Chanannel (1978) report that taurodontism occurred bilaterally in most cases while in this study and in Holt and Brook (1979) approximately equal numbers of tooth pairs were affected bilaterally and unilaterally. The sex ratio in this study of male 1: female 0.67 is similar to that of Holt and Brook (1979).

The prevalence of invaginated teeth in these Romano-Britons at $1.6 \%$ is lower than that for modern British, 4.1\% (Brook, 1974) and modern Swedish 3.0\% (Grahnen et al., 1959) samples.

Building on the comments of previous authors who remarked on a tendency for fused and cuneiform molar roots to be found together, this study provides evidence of the highly statistically significant association between these two anomalies. Similarly, the association of root number reduction of molars with congenital absence of third molars noted by Keene (1966) was found to be statistically significant in these Romano-Britons.

Stoy (1960), Stenvik et al. (1972) and Holt and Brook (1979) describe the association of taurodontism and hypodontia. In this study the association between taurodontism and hypodontia of third molars was shown to be highly significant statistically. This finding is compatible with a morphogenetic field effect with a varying influence anteroposteriorly.

The strong association between fused and cuneiform molar roots could indicate that the cuneiform root is one extreme of a continuous variation showing different degrees of confluence of roots and their canals. Complete root separation would represent the opposite extreme.

In conclusion, for root anomalies in this RomanoBritish population, the prevalence for skulls and for teeth, the sex distribution and bilateral symmetry has been established. The radiographic technique developed and the criteria used have high degrees of reproducibility. The statistically significant associations demonstrated in the Romano-Britons showed the relationship between fused roots and cuneiform roots as reductions in root number and shape and also their relationship with congenital absence of teeth. The gradients of anomalies observed were compatible with the concept of morphogenetic fields. The findings were also compatible with multifactorial etiology, showing continuous variation in root size and shape.

\section{LITERATURE CITED}

Alexandersen V. 1963.Double-rooted human lower canine teeth. In: Brothwell DR, editor. Dental anthropology. New York: Pergamon Press, p 235244.

Brabant H, Kovacs I. 1961. A contribution to the study of taurodontism in modern races and of its possible relation to the pyramidal roots of molars. Bull Group Rech Scient Stomot 4:232-286.

Brook AH. 1974. Dental anomalies of number, form and size: their prevalence in British schoolchildren. J Int Assoc Dent Child 5:37-53.

Brook AH, John CC. 1995. Dental anomalies of number and size in a Romano-British population. In: Radlanski RJ, Renz H, editors. Proceedings of 10th International Symposium on Dental Morphology. Berlin: C and M Brunne GbR, p 177-180.

Curzon MEJ.1973. Three-rooted mandibular permanent molars in English Caucasians. J Dent Res 52:181.

Dixon GH, Stewart RE. 1976. General aspects of anomalous tooth development. In: Stewart R E and Prescott G H, editors. Oral Facial Genetics. St Louis: C V Mosby, p 133-135.

Grahnen H, Lindahl B, Omnell KA. 1959. Dens invaginatus: I. a clinical roentgenological and genetical study of permanent upper lateral incisors. Odont Revy 10:115-137.

Hallett GEM. 1953. The incidence, nature and clinical significance of palatal invaginations in the maxillary incisor teeth. Proc R Soc Med 46:491-499.

Holt RD. 1976. The prevalence of root anomalies in children. MSc Thesis, University of London.

Holt RD, Brook AH. 1979. Taurodontism: a criterion for diagnosis and its prevalence in mandibular first permanent molars in a sample of 1,115 British schoolchildren. J Int Assoc Dent Child 10:41-47.

Keene HJ. 1966. A morphological and biometric study of taurodontism in a contemporary population. Am J Phys Anthropol 25:208-209.

Molnar E, Horvath G. 1995. Developmental anomalies of the teeth in historic skeletal samples. In: Radlanski RJ, Renz H, editors. Proceedings of the 10th International Symposium on Dental Morphology. Berlin: C and M Brunne GbR, p 377-385.

OehlersFA.1958. The radicular type of dens invaginatus. Oral Surg Oral Med Oral Pathol 11:251-260.

Pedersen PO. 1949. The East Greenland Eskimo dentition: numerical variations and anatomy. Copenhagen: C A Retzels Forlag.

Ross IF, Evanchik PA. 1981. Root fusion in molars: incidence and sex linkage. J Periodontol 52:663667.

Scott GR, Alexandersen V. 1992. Dental morphological variation among Medieval Greenlanders, 
Icelanders and Norwegians. In: Smith P, Tchernov $\mathrm{E}$, editors. Structure, function and evolution of teeth. London: Freund Publishing House, p 467-490.

Shifmann A, Chanannel I. 1978. Prevalence of taurodontism found in a radiographic dental examination of 1,200 young adult Israeli patients. Community Dent Oral Epidemiol 6:200-203. Souza-Freitus J A, Lopez E S, Casati-Alvares L. 1971. Anatomic variations of lower first permanent molar roots in two ethnic groups. Oral Surg Oral Med Oral Pathol 31:274-278.
Stenvik A, Zachrisson BU, Svatun B. 1972. Taurodontism and concomitant hypodontia in siblings. Oral Surg Oral Med Oral Pathol 33:841-845.

Stoy PJ. 1960. Taurodontism associated with other dental anomalies. Dent Pract Dent Rec 10:202-205.

Tamse A, Kaffe I. 1981. Radiographic survey of the prevalence of conical lower second molar. Int Endod J 14:188-190.

Winter GB, Brook AH. 1989. Tooth abnormalities. In: Rowe HR, Alexander AG, Johns RB, editors. A comprehensive guide to clinical dentistry. London: Class Publishing, p 55-103. 